\title{
Processos movidos contra cirurgiões-dentistas no Conselho Regional de Odontologia - seção Pará - nos últimos sete anos
}

\author{
Processes against dentists at "Conselho Regional de \\ Odontologia - seção Pará" in the last seven years
}

Clarissa Mendes Lobato de Oliveira(1), Erika Seabra Martins Bezerra(1), Isabella Haber

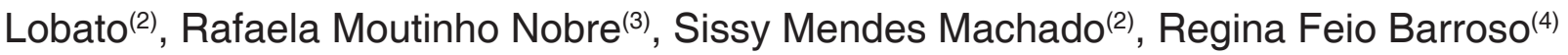

Oliveira CML, Bezerra ESM, Lobato IH, Nobre RM, Machado SM, Barroso RF. Processos movidos contra cirurgiõesdentistas no Conselho Regional de Odontologia - seção Pará - nos últimos sete anos. Saúde, Ética \& Justiça. 2010;15(2):46-52.

RESUMO: O crescente número de processos cíveis e criminais envolvendo profissionais da área da saúde no Brasil, inclusive cirurgiões-dentistas, motivou o presente estudo, voltado a pesquisar e analisar processos instaurados contra cirurgiões-dentistas no período de 2003 até 2009 no Conselho Regional de Odontologia do Pará (CRO-PA). A amostra constou de 57 processos cujos dados permitiram inferir que a propaganda ilegal foi a principal causa para a abertura de processos (10\%), seguida por intercorrências no tratamento cirúrgico $(10,5 \%)$. Dentre os processos finalizados, $57,6 \%$ foram arquivados e $42,4 \%$ foram julgados, mostrando que na maior parte das vezes ocorreu o entendimento entre as partes envolvidas.

DESCRITORES: Ética odontológica; Relações dentista-paciente/ética; Legislação odontológica/ética; Odontologia/ legislação \& jurisprudência.

(1) Odontopediatra, mestranda em Odontologia da Universidade Federal do Pará.

(2) Ortodontista, mestranda em Odontologia da Universidade Federal do Pará

(3) Cirurgiã Buco-Maxilo-Facial, mestranda em Odontologia da Universidade Federal do Pará.

(4) Professora Orientadora do Curso de Pós-graduação Nível Mestrado em Odontologia da Universidade Federal do Pará.

Endereço para correspondência: Larissa M. L. de Oliveira. Rua Domingos Marreiros, 280 Apt. 2701, Belém, Pará, Brasil. CEP: 66055-210. E-mail: clalobato@ hotmail.com. 


\section{INTRODUÇÃO}

noção da responsabilidade civil
e profissional na sociedade e,
principalmente, na classe odontológica vem aumentando nos últimos anos, haja vista a ocorrência dos inúmeros processos judiciais e administrativos envolvendo o paciente e o profissional.

Reformas na Constituição Federal de 1988, no Código de Proteção e Defesa do Consumidor em 1991 e no Código Civil Brasileiro proporcionaram mudanças no comportamento da sociedade e, desta forma, tem sido observado um aumento no número de processos éticos e judiciais contra a classe odontológica.

A responsabilidade profissional subdividese em responsabilidade moral e responsabilidade social. A primeira é aquela que se submete à própria consciência de cada pessoa, ou também chamada bom senso, mais ligado a conceitos morais e de formação do que às esferas judicial ou social. E, a segunda, a responsabilidade social, é aquela policiada por autoridade externa, que impõe penalidades quando os atos atingem outras pessoas e quando a penalidade refere-se aos atos praticados no exercício de determinada profissão (responsabilidade profissional) ${ }^{1}$.

Para que se avalie a responsabilidade civil do cirurgião-dentista são imprescindíveis as seguintes exigências legais: o agente, o ato, a culpa, o dano e o nexo de causalidade. O agente é o cirurgião dentista (CD) devidamente legalizado para o exercício profissional. O ato seria a ação profissional caracterizada como ilícita. A culpa resulta de uma ação do agente, que traga possíveis resultados lesivos. O dano não consiste apenas no resultado lesivo, mas sim quando este resulta de atitude de negligência, imprudência ou imperícia por parte do agente. Por fim, o nexo da casualidade é a ligação entre a ação ou omissão do profissional e o dano verificado no paciente ${ }^{2,3}$.

Para efeito jurídico e ético, o dano causado por um cirurgião-dentista a seu paciente pode ser causado por imprudência, negligência ou imperícia. A imprudência ocorre quando se supõe que o profissional agiu com confiança extrema, ou sem cautela. A negligência, quando 0 ato praticado pelo cirurgião-dentista é displicente ou omissivo. Já a imperícia é definida como a situação na qual há desconhecimento das técnicas aplicadas ou de outros conhecimentos fundamentais para 0 atendimento.
Deste modo, o cirurgião-dentista pode ser julgado na esfera administrativa, pelos Conselhos Regional e Federal de Odontologia; bem como Judicial, em ações de caráter penal e civil ${ }^{1,3,5,6}$. Os julgamentos da Justiça comum seguem os preceitos do Código Penal e Civil, enquanto os relacionados aos Conselhos se baseiam no Código de Ética Odontológica ${ }^{7}$.

O cirurgião-dentista, muitas vezes, é prejudicado no decorrer do processo devido à falta de clareza das informações nos prontuários das vítimas 4 . Outro motivo que tem prejudicado os profissionais é a falta de informação sobre sua responsabilidade profissional, o que pode tornar o profissional vulnerável à ações nas três esferas: jurídica, civil e administrativa.

Segundo Bittencourt ${ }^{8}$, a insatisfatória formação ética do médico contribui para a ocorrência de desvios de conduta no exercício da profissão. Portanto, os pontos fundamentais que devem ser abordados desde a graduação para prevenir o erro médico são: aprimoramento da relação médico-paciente e da comunicação entre médicos, pacientes e familiares; valorização do compromisso social do médico; ênfase na educação continuada e no trabalho em equipes multidisciplinares; além de incentivo ao correto preenchimento dos registros médicos. Para atingir estes objetivos faz-se necessário que o ensino de Ética e Bioética seja mais abrangente, não apenas voltado à deontologia, à apresentação dos artigos do Código de Ética, mas, também, à discussão das questões do dia-a-dia que estão intimamente ligadas à conduta médica e seus dilemas morais.

Devido ao fato de a Odontologia não ter mostrado trabalhos que demonstrassem a imprevisibilidade das respostas biológicas a determinados tratamentos ${ }^{9}$, existem controvérsias quanto à natureza da obrigação do cirurgiãodentista. Alguns autores como Calvielli ${ }^{6}$ afirmam que o papel do profissional é devolver a saúde ao paciente, buscando o melhor resultado diante das condições existentes. Outros autores ${ }^{10}$ acreditam que 0 trabalho do profissional em beneficiar o paciente com o resultado esperado por ele, resume esta relação, independente de fatores modificadores.

Oliveira $^{10}$ dividiu as especialidades odontológicas naquelas consideradas de resultado, como Dentistica Restauradora, Odontologia Legal, Odontologia Preventiva e Social, Ortodontia, Prótese Dental, Radiologia; e aquelas nas quais o resultado varia caso a caso: Cirurgia e Traumatologia Buco-Maxilo-Facial, Endodontia, 
Odontopediatria, Patologia Bucal, Ortodontia, Periodontia e Prótese Buco-Maxilo-Facial. A última especialidade registrada no conselho, Implantodontia, é considerada como especialidade de resultado.

Juridicamente, existem dois momentos a serem considerados na distinção entre obrigação de meio e de resultado. Primeiro, deve-se avaliar de que forma a obrigação foi contratada, se o contratado se obrigou a atingir determinado resultado e se esta promessa foi o motivo que determinou o contrato. Caso positivo, o profissional deve alcançar este objetivo, senão responderá pela inexecução do contrato ${ }^{11}$.

O Código de Ética Odontológico de $2006^{12}$ (aprovado pela Resolução CFO de 2003) revogou a versão de 1983, assegurando a todos o direito a uma ficha ou registro odontológico, acesso a todas as informações sobre sua saúde, com uma linguagem compreensível, e cópias de exames laboratoriais, raios-x e avaliação psicológica entre outros (Cap. III, Art. $5^{\circ}$ ). Devem constar na documentação do paciente: o prontuário, os livros de agendamento, modelos, radiografias etc. Segundo o Código, o prontuário deve ser mantido pelo cirurgião-dentista em arquivo próprio, porem não há especificação quanto ao tempo que o mesmo deve ser guardado.

Segundo o Conselho Federal de Odontologia determinou em 1998, todos os documentos emitidos pelo cirurgião-dentista devem ser escritos à tinta, com letra legível e com cópia. Porém, com o avanço da tecnologia, é observado o uso de prontuários eletrônicos e a digitalização da documentação, com a vantagem de facilitar o arquivamento e diminuir a utilização de papel ${ }^{13}$. O prontuário digitalizado é gravado magneticamente em um disco garantindo sua existência física e podendo, quando necessário, ser impresso, passando assim a existir na forma impressa ${ }^{15-17}$, conforme prevê a legislação.

De acordo com o Código Civil Brasileiro, as ações pessoais prescrevem em 3 anos após a ciência do ato; enquanto o Código de Defesa do Consumidor afirma: Prescreve em 5 anos a pretensão à reparação pelos danos causados pelo serviço... iniciando-se a contagem do prazo a partir do conhecimento do dano e de sua autoria ${ }^{13}$. Além do valor clínico, a documentação odontológica reveste-se de importância médico-legal-jurídica que, em certos casos, poderá ser decisiva ${ }^{14}$.

A necessidade de registrar as diversas fases e processos de atendimentos e a importância de tal documentação para o cirurgião dentista pode ser percebida neste artigo, que decorre de pesquisa realizada a partir de 2004 no Conselho Regional de
Odontologia do Estado do Pará. Dentre os casos analisados, 55,5\% dos processos abertos contra cirurgiões-dentistas no CRO - Pará no ano de 2004 poderiam ter sido evitados caso os prontuários estivessem completos.

É importante citar que a falta de comunicação entre profissional e paciente foi um fator agravante nesses casos, respondendo por um percentual de $66,6 \%$. Quanto à conclusão dos processos, 66,6\% deles resultaram em acordo entre profissional e paciente, $22,2 \%$ foram arquivados, enquanto em $11,1 \%$ os acusados foram absolvidos ${ }^{18}$. As principais causas dos processos referem-se a tratamentos endodônticos $(38,8 \%)$, cirurgias $(33,3 \%)$, próteses e os outros $(11,1 \%)$, sendo os $5,5 \%$ restantes relacionados a diferentes causas.

A esfera administrativa, que compreende os Conselhos de Classe, é geralmente a primeira esfera que o reclamante aciona, pois a partir de uma condenação do profissional no seu conselho, ficam mais fáceis as causas civis e judiciais.

Diante da escassa literatura sobre 0 resultado de processos contra profissionais da saúde e, especialmente, daqueles relacionados aos cirurgiões dentistas, é apresentado este artigo voltado à especificidade regional do CRO-PA. Entendemos que é de fundamental importância para os profissionais da área conhecer as causas e os resultados do julgamento destes processos, a fim de que seja possível evitar desgastes com processos, através de sutis mudanças de conduta e melhora da relação entre profissional e paciente.

\section{OBJETIVO}

Realizar levantamento e análise dos processos finalizados contra Cirurgiões-dentistas registrados no Conselho Regional de Odontologia, secção Pará, no período de 2003-2009.

\section{MATERIAIS E MÉTODO}

O projeto de pesquisa foi submetido à avaliação do Comitê de Ética em Pesquisa (CEP) da Universidade Federal do Pará (UFPA), de acordo com o previsto na Resolução 196/96 do Conselho Nacional de Saúde. O protocolo de pesquisa foi regularmente encaminhado e aprovado pelo Comitê de Ética da UFPA e, mediante o consentimento por escrito do Presidente do CRO Pará, foi iniciada a pesquisa.

O total de processos que constituíram a amostra no período de 2003 a 2009 foi de 57 . Os dados referentes aos processos finalizados 
Oliveira CML et al. Processos movidos contra cirurgiões-dentistas no Conselho Regional de Odontologia.

foram relatados pelo Presidente de Comissão de Ética da instituição, no sentido de preservar a confidencialidade dos autos e o sigilo processual. Ou seja, os pesquisadores não tiveram acesso direto aos processos abertos no CRO-PA, os mesmos apenas perguntavam as informações pertinentes ao trabalho e obtinham respostas do Presidente da Comissão de Ética da instituição, sob a prerrogativa de não haver identificação dos nomes dos cirurgiões-dentistas constantes nos processos.

A investigação consistia em conhecer a causa do processo, se houve julgamento e qual o resultado deste. Nos casos em que não houve julgamento, a forma como o processo foi encerrado foi analisada.

Neste estudo foram descartadas denúncias que não resultaram em abertura de processo, assim como alguns processos abertos em 2009, que não tinham sido resolvidos até o fechamento da pesquisa. Os dados levantados foram submetidos à análise descritiva percentual (regra de três simples) e armazenados em um sistema aplicativo Exceß no sistema operacional Windows $X P \circledast$.

\section{DISCUSSÃO}

A análise dos resultados deste estudo aponta no sentido de os Conselhos atuarem de forma independente, buscando sempre a justiça, um dos referenciais básicos da Bioética, sem deixar de ter presente a importante responsabilidade de proteger a vulnerabilidade da sociedade. O CROPA mostrou ser extremamente cuidadoso com o sigilo de seus processos, na medida em que não permitiu o acesso direto a eles, apenas a consultoria de informações através do Presidente de seu Conselho de Ética.

Embora muitos cirurgiões-dentistas tenham sido indiciados no Conselho, pouco se tem estudado sobre a freqüência e especificidades destes processos no estado do Pará. A pesquisa verificou que no período estudado o total de processos foi de 57 e a propaganda indevida foi a principal causa relacionada à sua abertura, representando $10 \%$ do total (Tabela 1).

Tabela 1: Análise e causas de processos no CRO-PA, Pará, 2003-2009

\begin{tabular}{|c|c|c|c|c|c|c|c|c|}
\hline Causas & 2003 & 2004 & 2005 & 2006 & 2007 & 2008 & 2009 & Total \\
\hline Prescrição irregular & 1 & - & - & - & - & - & & 1 \\
\hline Propaganda indevida & - & 1 & 4 & 3 & - & 4 & 6 & 18 \\
\hline Exercício ilegal & - & - & 1 & - & - & 2 & 1 & 4 \\
\hline Tratamento ortodôntico & - & 2 & - & 1 & - & 1 & 1 & 5 \\
\hline Procedimento cirúrgico & 1 & - & - & - & - & - & 5 & 6 \\
\hline Procedimento em dentística & - & - & 2 & - & - & - & - & 2 \\
\hline Procedimento em endodontia & - & - & - & - & 2 & - & 1 & 3 \\
\hline Procedimento em prótese & 1 & - & 1 & - & - & - & 2 & 4 \\
\hline Atestado ilegal & - & - & - & - & 1 & - & 1 & 2 \\
\hline Insatisfação no tratamento & - & - & - & - & - & 3 & 3 & 6 \\
\hline Erro técnico de colega & - & - & - & - & - & - & 1 & 1 \\
\hline Exploração de colega em emprego & - & - & - & - & - & - & 3 & 3 \\
\hline Abandono de paciente & - & - & - & - & - & 1 & 1 & 2 \\
\hline Total & & & & & & & & 57 \\
\hline
\end{tabular}

Fonte: Dados da pesquisa. 
Oliveira CML et al. Processos movidos contra cirurgiões-dentistas no Conselho Regional de Odontologia.

Considerando-se que a propaganda indevida pode ser facilmente evitada com o cumprimento dos artigos 32-35 (Cap. XIV, seção 1) presentes no Código de Ética Odontológica ${ }^{12}$, este fato retrata o desconhecimento ou desinteresse da classe na sua legislação. Porém, é necessário salientar que no currículo acadêmico consta o estudo deste código, além do fato de ele ser fornecido ao cirurgiãodentista no ato de sua inscrição no Conselho Regional de Odontologia- Secção Pará (CRO-PA).

$A$ insatisfação com o tratamento originou abertura de seis processos $(n=6)$, sendo esta a segunda maior causa de processos. Este fato é preocupante, visto que na própria literatura odontológica há controvérsia sobre o tipo de atividade desempenhada pelo cirurgião-dentista.

Dentre as reclamações nas especialidades, a cirurgia originou a maior parte dos processos no período avaliado ( $n=6)$, seguida pela ortodontia ( $n$ $=5$ ). As causas de processos nestas especialidades variam, sendo a maior parte devido à falta de entendimento entre o paciente e o profissional, o que corrobora com um estudo publicado em 1999, no qual se verificou que, dos 276 processos éticoadministrativos analisados entre janeiro de 1994 e junho de 1995, 25 (9,05\%) eram relacionados à ortodontia ${ }^{17}$.

À medida que aumenta o volume de tratamento ortodôntico nos últimos anos observamse muitas queixas informais a este respeito. No entanto, nos processos concluídos no CRO-PA entre 2003-2009, houve conciliação entre paciente e profissional.

Outra causa de processo que, apesar de pequena estatisticamente $(1,7 \%)$, merece destaque pelo ineditismo nesta esfera administrativa, é a exploração de colegas na profissão. No ano de 2009 houve três processos nesta área, o que deve servir de alerta à classe odontológica do estado do Pará e do país inteiro, onde ainda é possível observar clínicas administradas por cirurgiõesdentistas habilitados, que recebem porcentagem dos honorários dos procedimentos realizados por colegas.

De acordo com o Código de Ética Odontológica ${ }^{12}$, é vetada esta prática. O profissional poderá contratar outro cirurgião-dentista através de contrato de trabalho ou pela CLT, porém jamais se beneficiar financeiramente do trabalho realizado pelo colega. Desta forma, estes dados servem de alerta para que a classe não fira os seus próprios direitos e infrinja seu código de ética. Nesta situação também cabem outras formas de processos, em outras esferas, de acordo com o código civil e trabalhista.

Dentre os processos iniciados ( $n=57), 14$ foram julgados e 34 arquivados, o que implica dizer que $57,6 \%$ dos casos não foram a julgamento (Gráfico 1). O resultado permite deduzir que na maioria das vezes houve o entendimento entre as partes envolvidas, corroborando os resultados obtidos em estudo prévio da instituição, realizado em $2004^{19}$. Esses estudos confirmam a perspectiva conciliadora do CRO-PA.

Gráfico 1: Processos arquivados versus julgados, CRO-PA 2003-2009

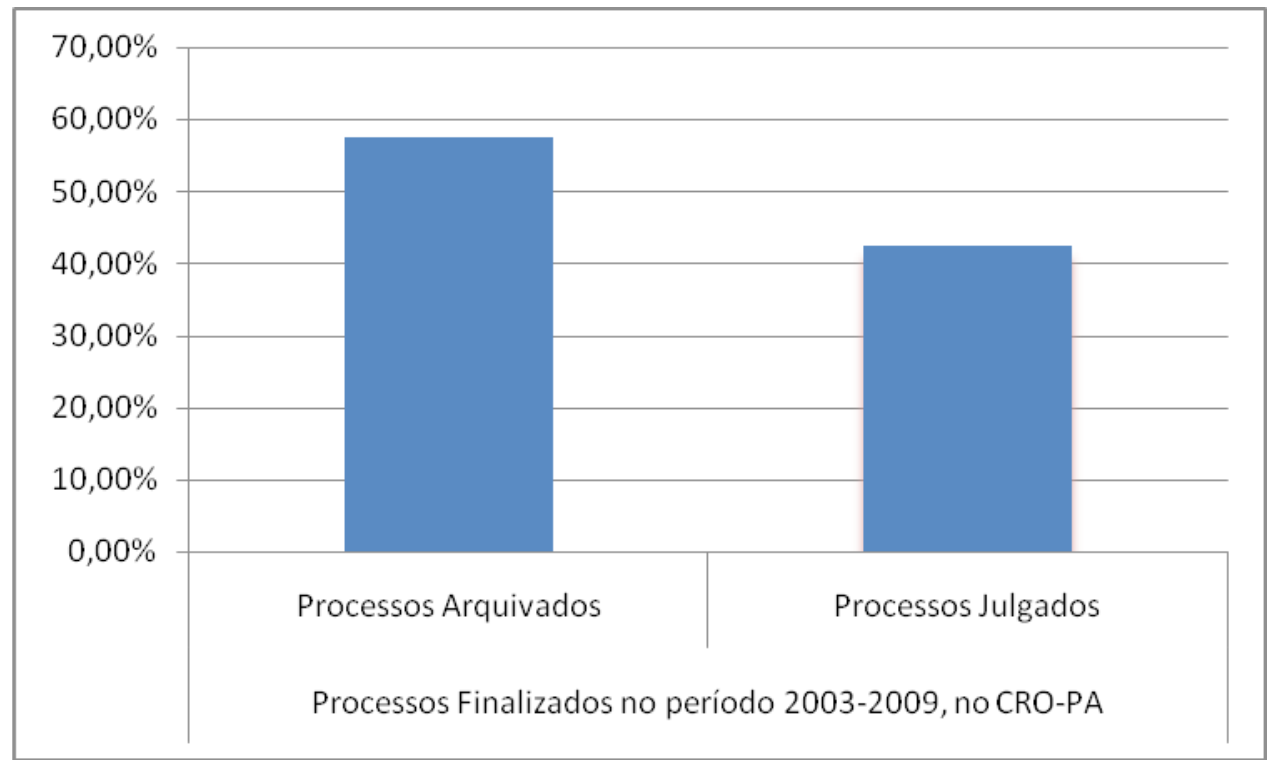


Oliveira CML et al. Processos movidos contra cirurgiões-dentistas no Conselho Regional de Odontologia.

Os demais processos $(n=9)$ ainda estão em andamento e referem-se aos anos de 2008 ( $n=$ 1) e $2009(n=8)$, respectivamente. Apesar destes dados, não se pode concluir que houve morosidade na resolução de processos, uma vez que só no ano de 2009 foram iniciados 24 processos, obtendose, desta forma, resolução de $66,7 \%$ no período. Também é preciso considerar que no ano de 2009 houve um aumento considerável do número de processos instaurados, representando $42,1 \%$ do total de processos iniciados no período estudado, o que caracteriza uma maior atuação do CRO-PA.

Dentre os $42,4 \%$ dos casos julgados, as penalidades envolveram advertências, censuras confidenciais e pena pecuniária. Observa-se que, entre as penalidades possíveis, ocorreu um mínimo prejuízo ao profissional, sendo que, em todos os casos, os denunciantes também tiveram suas queixas solucionadas.

\section{CONCLUSÕES}

Diante dos resultados finais, pode-se concluir que os cirurgiões-dentistas não estão devidamente preparados em relação aos conhecimentos éticos e legais pertinentes ao exercício profissional, tornando-se vulneráveis em casos de litígios.

Daí porque a maior parte dos processos finalizados no período de 2003 a 2009 deveu-se à propaganda ilegal; sem que houvesse prevalência expressiva de processos de uma dada especialidade em detrimento das outras.

A maior parte dos processos $(57,6 \%)$ não chegou a julgamento, resultando no entendimento entre as partes. Isto evidencia a atuação positiva da comissão de ética, mostrando o importante papel de mediador do CRO-PA, evitando que os processos evoluíssem para outra instância, pois na maior parte das vezes estes ocorrem devido à falta de comunicação entre os envolvidos. Dos profissionais julgados, as penalidades foram na sua maioria advertências confidenciais, testemunhando a postura do CRO-PA como agente conciliador.

De acordo com os resultados obtidos, é importante salientar que os pacientes desconhecem e/ou não intencionam buscar danos morais porventura causados na ação, o que pode servir de alerta aos profissionais de saúde, para que se documentem melhor e realizem um criterioso contrato de prestação de serviço, a fim de evitar que no futuro aumente o número e a gravidade das denúncias.

Oliveira CML, Bezerra ESM, Lobato IH, Nobre RM, Machado SM, Barroso RF. Processes against dentists at "Conselho Regional de Odontologia - seção Pará" in the last seven years. Saúde, Ética \& Justiça. 2010;15(2):46-52.

ABSTRACT: The large amounts of criminal and civil processes in Brazil involving people who work in health area, especially dentists have encouraged the authors to review its current causes. A research in CRO was done with the aim to analyze the processes against dentists between 2003 and 2009. A total of 57 papers were studied and the informations could let us conclude that the main causes were illegal advertising (10\%) and improper surgery treatment (10.5\%). Among the finalized processes, $57.6 \%$ were closed and $42.4 \%$ were judged. It seems that there was an agreement between the dentist and the patient in most cases.

KEY WORDS: Ethics, dental; Dentist-patient relations/ethics; Legislation, dental/ethics; Dentistry/legislation \& jurisprudence.

\section{REFERÊNCIAS}

1. Calvielli ITP. Responsabilidade profissional do cirurgião dentista. In: Silva M. Compêndio de odontologia legal. Rio de Janeiro: Medsi; 1997. p.399-411.

2. Simonetti FAA. Responsabilidade civil do cirurgiãodentista. Rev APCD. 1999;53(6):449-51.

3. Antunes FCM, Daruge E, Daruge Jr. E. O cirurgiãodentista frente à responsabilidade civil. JAO. 2001;4(24):45-51.

4. Araújo IC, Lima FVP, Martins EL. Revista do conselho regional de odontologia do Piauí. O prontuário odontológico: guardar até quando? [citado em 14 dez. 2007]. Disponível em: http://www.cropi.org.br.

5. Ferreira RA. No banco dos réus. Rev Assoc Paul Cir Dent. 1995;49(4):58-267.

6. Calvielli ITP. Natureza da obrigação assumida pelo C.D. nocontratodelocaçãodeserviçosodontológicos. Rev Assoc Paul Cir Dent.1996;56(4):315-8 .

7. Lucas SD. Ética e processos éticos. Rev CRO-MG. 1999;5 (1):54-9. 
Oliveira CML et al. Processos movidos contra cirurgiões-dentistas no Conselho Regional de Odontologia.

8. Bittencourt AG, Neves NMBC, Neves FBCS, Brasil ISPS, Santos LSC. Análise do erro médico em processos ético-profissionais: implicações na educação médica. Rev Bras Educ Med. 2007;31(3): 223-8.

9. Menegale JG. Responsabilidade profissional do cirurgião-dentista. Rev Forense. 1939;80:55-62.

10. Oliveira MLL. Responsabilidade civil odontológica. Belo Horizonte: Ed. Del Rey; 2000.

11. Souza NTC. Responsabilidade civil e penal do médico. São Paulo: Ed. LZN; 2006.

12. Maia CAE, Ferres MAL. Aspectos éticos e legais da ortodontia no Brasil. Ortodontia. 1999;32(2):67-81.

13. Conselho Federal de Odontologia. Código de ética odontológico. Rio de Janeiro; 2006.

14. Junior VSN, Serrano YAP. Código de defesa do consumidor interpretado. São Paulo: Editora Saraiva; 2003.

15. Modaffore PM. Dental review. Uma nova realidade na odontologia: os processos de responsabilidade profissional [citado em 13 jun. 2008]. Disponível em: http://www.dentalreview.com.br.

16. Green SR. Computers are in dentistry's future. Dent Encon. 1994;84(8):85-8.

17. Lackey AD. In your face interface is the hub. Dent Enc. 1997;87(8):20-8.

18. Pereira CB. Legalidade dos arquivos digitais na odontologia [citado em 25 jun. 2008]. Disponível em: http://www.cleber.com.br/legalid4html.

19. Calderaro ACCS, Salheb LM. Erros odontológicos responsabilidade civil do cirurgião-dentista. Pará: Centro CESUPA; 2005.

Recebido em: 23/06/2010

Aprovado em: 23/08/2010 